\title{
REFRAMING BEST ALTERNATIVES TO NEGOTIATED AGREEMENTS IN REPRESENTATIVE NEGOTIATIONS IN SPORTS
}

\author{
Hristina Dobreva \\ Rakovski National Defence College (Bulgaria)
}

\begin{abstract}
The paper starts with differentiating between the positional and interest-based negotiation styles for reaching the Best Alternative to a Negotiated Agreement (BATNA). It outlines the main problems of positional bargaining and the role of agents in representative negotiations in sports. The paper aims at specifying negotiation styles and tactics/games that could produce optimal win-win solutions in sports. It focuses on the need of tactical flexibility, timing, collaboration, issue-linkage and leverage creation that could possibly reframe BATNAs for reaching mutual gain agreements and optimal win-win solutions.

The paper aims is to propose solutions for reaching agreements in representative negotiations in sports. The methodology's starting point is BATNA. The analytical framework includes both choosing the appropriate negotiation style (positional or interest-based) and tactics (negotiation games) to end up with a given strategy. Principled negotiation and mutual gain approach are suggested as solutions.

The results of the analysis could be summarized in four categories. The first is the importance of considering the specifics of sports negotiations, especially the advantages and disadvantages of using agents as representatives. Here short versus long-term interests have to be weighed. The second is the advancement of issue linkages, creative alternatives for win-win solutions, leverage and appropriate bargaining style. The third is the focus on the process of reframing BATNAS as a process of evaluating alternatives, seeking leverage but maintaining credibility and flexibility. The fourth is the application of the mutual gain approach to expand the frontier of possibilities. Here the most important is the brainstorming session and the concept of the next best solution.
\end{abstract}

Keywords: BATNA; negotiation; tactical games; sports

\section{Introduction}

It is utterly important to formulate a winning strategy in sports negotiations. This strategy starts with deciding on the negotiation style and tactics and should represent one's creativity and build credibility. Styles are better to be decided on 
even in the pre-negotiation period. Some tactics are better than others. However, probably timing and flexibility are the factors that matter most.

The purpose of the article is to observe specifics of sport negotiations involving agents and project these findings to other similar areas of representative negotiation as law, real estate, trade unions and even politics (where MPs, ambassadors and emissaries are people's representatives worldwide). The question is whether it is possible for mutual gain bargaining to be based on the appropriate negotiation game? Could we reframe our BATNAs in this process? BATNAs are of course time dependent.

\section{Methodology}

\section{Analytical Framework-BATNA}

The analytical framework stems from a webinar in "Essentials of Negotiation" led by Dr. Evan Hoffman of the Canadian International Institute of Applied Negotiation(CIIAN). The program uses a Negotiation Aide Memoire as a framework adapted from the Program on Negotiation (PON) at Harvard University. The development of a negotiation strategy starts first with considering the negotiation style (positional or interest-based) and second with considering the negotiation tactics (11 negotiation games).

The starting point of this Memoire is BATNA (best alternative to a negotiated agreement) and the negotiation of most value is the interest-based negotiation as opposed to positional negotiation. In fact principled negotiation is a combination of distributive and integrative negotiation.

\section{Positional and Interest-based Negotiation}

Table 1. Basic comparison of negotiation styles

\begin{tabular}{|l|l|}
\hline Positional negotiation & Interest-based negotiation \\
\hline $\begin{array}{l}\text { 1. Period: short-term } \\
\text { 2. Corresponding game theory: zero-sum } \\
\text { games, fixed pie }\end{array}$ & $\begin{array}{l}\text { 1. Period: short and long term } \\
\text { games and reassurance, can expand the pie }\end{array}$ \\
\hline $\begin{array}{l}\text { 3. Negotiation theory: distributive- a single } \\
\text { issue focus }\end{array}$ & $\begin{array}{l}\text { 3. Negotiation theory: Integrative, mutual } \\
\text { gain-relationship centered }\end{array}$ \\
\hline $\begin{array}{l}\text { 4. Negotiation games-own interest, } \\
\text { positional, chicken game, lock-in, threat, } \\
\text { time pressure }\end{array}$ & $\begin{array}{l}\text { 4. Negotiation games-favors and ledgers, } \\
\text { linkage, split the difference, compromise }\end{array}$ \\
\hline 5. Unethical, unnatural & 5. Ethical \\
\hline
\end{tabular}

\section{The 11 Negotiation Games}

The 11 negotiation games or tactics ${ }^{1}$ are applied and they may be listed as:1) take care of one's interest (real want), 2) positional game (waiting for an offer after stated initial position), 3) favors and ledgers (balanced sheet), 4) lock-in situation (hands tied), 5) linkage, 6) Edward's game (opponent commits first without the promise of 
later commitment of the other party), 7) split the difference (meet half way), 8) game of chicken, 9) compromise, 10) threat, 11) time pressure (take now or lose forever).

Generally, in the case of sports negotiations, positional game is not working well, the favors and ledgers game offers a balance sheet, the lock-in game works under conditions of constraint, the linkage game offers a trade-off, the Edward's game teaches one to commit late, the chicken game works when the opponent has the only alternative of committing to the offer, the time pressure game is a variant of the threat game.

Principled negotiation is an all-purpose strategy (Fisher and Ury 1991, xix). This method focuses on basic interests, mutually satisfying options and consensus (Fisher and Ury 1991, 14). It is a solution to the problem of positional bargaining which becomes even more obvious when more people are involved (Fisher and Ury 1991, 7).

\section{Results \\ Specifics of Sports Negotiations: Advantages and Disadvantages of Using Agents}

There are at least eight different types of sports contracts (salary, player, coaching, endorsement, branding campaign, sponsorship, right to name, publishing and so on) (Sports Contract Negotiation, Brian Murphy). The focus of the article is on sports contract negotiations. The main advantage lies in the expertise of the agent during the negotiation process when the agent can act as a match-maker between players and teams (p.7, Win-Win or Hardball?...).

Representative negotiations take place indirectly. There are three forms of expertise that an agent may possess to be considered a representative in the negotiation: substantive knowledge (in a particular domain), process expertise (specific for the negotiation process) and special influence (or lobbying) (Rubin and Sander 1988, 396). Impartiality or detachment is another important reason for using agents (especially when direct negotiation leads to conflicts) as well as tactical flexibility (Rubin and Sander 1988, 397) although the latter is specific to competitive, zero-sum games. In the case of problem-solving bargaining style, agents can be helpful with proper articulation of interests, options and alternatives, especially during the brainstorming session (Rubin and Sander 1988, 398).

Two distinct forms of sports contract negotiations are the rookie class and free agency negotiations (Steinberg 2016). Usually both in the case of the NBA (National Basketball Association) and the NFL (National Football League), the rookie has to sign a contract with two guaranteed years and two team options and the agent either charges $4 \%$ of the player's compensation or charges nothing, waiting for the second contract. It is important for agents to educate rookies on labor laws or collective bargaining agreements in order for rookies to be aware of their rights and responsibilities beyond compensation. Free agency on the other hand is a future opportunity which comes 
after a year in the NBA and after four years in the NFL, and agents have to prepare in advance, monitoring team rosters and balancing opportunities with the priorities of the client which are not always monetary ones. Agents are the ones to decide on the proper timing of signing a contract, considering the fair market value of a free agent and avoiding lies as a negotiation strategy.

Usually it is best when sports agents are attorneys that practice sports law (Davis 2001, 211). The problems of agent-player relationships may be attributed to the fact that many of the services, provided by agents are not established in standard contacts but rather rely on good faith (Davis 2001, 224). Agents may represent not only athletes but also coaches, educational institutions, sports facilities, and even act as counsel for a sports league or team. It is better if agents possess a broad expertise, extending beyond the actual signing of the contract. This expertise comes under the form of the following functions: contract negotiations, tax and financial planning, money and investment management, estate planning, endorsements, physical health consultations, post-career development, legal and insurance consultations (Davis 2001, 240).

A positive aspect of using agents is that they serve the role of buffers in future player-agent relations (Shropshire 2009, 138). According to the leading scholarly article on the topic, called "When Should We Use Agents?", (Rubin and Sander, 1988) the use of agents is welcome under three circumstances: reliance on special expertise, achieving tactical flexibility and avoiding confrontation during direct negotiation (Shropshire 2009, 144). The agent has the role of a mediator or communicator especially in the case of misunderstanding (Fisher and Ury 1991,33). This role is similar to the one of an interpreter.

There are several drawbacks of using agents. The first lies in the nature of the agent-client relationship, which is money centered as agents typically get $4 \%$ to $10 \%$ of their clients' salaries. This may create a conflict of interests between the shortterm money interest of the agent and the long-term career development interest of the client (p.7, Win-Win or Hardball?..). For this reason a lot of players become free agents. However, this is mostly true of sport veterans rather than rookies as the latter are constrained by the lack of alternatives in their initial contracts with teams. Here comes the second disadvantage of using agents-extreme reliance on expertise of others. The third disadvantage is that agents in sports may replace ZOPA (Zone of possible agreement) with NOPA (No possible agreement) (p.8, Win-Win or Hardball?..). If BATNA equals NOPA, pressure is applied by agents as well as crafty moves to outwit the counterpart, which resembles positional negotiations. Of course this may lead to the client gaining competitive advantage (p.6, Win-Win or Hardball?..) because of agent's skills, which is a positive outcome in a zero-sum game.

The negative aspect of focusing on money instead of building relationships is generally explained by the financial incentives of agents as they are paid once the deal is closed (Shropshire 2009, 142). Thus this becomes their main concern as opposed to focusing on the potential of future negotiations with the management 
and coaches. Thus they focus on short-term tangible aspects instead of long-term intangible ones as reputation and public perception of the player. The bottom line is that interests of agents and players are not always aligned.

Two problems of the principal-agent relationship are emphasized in the agency theory (Bala 2019, 3): 1) conflict of interest as the compensation may be the leading incentive for the agent and 2) risk-sharing when both parties have different views towards risk. Four main problems of using agents can be listed: 1) risk of distortion of information, 2) excessive reliance on indirect communication, 3) creation of unwanted coalitions and 4) conflicting interests and problems of "ownership" (Rubin and Sander, 1988, 399 - 400). The conflict of interests in representative negotiation resembles the principles of asymmetric war (Dimov 2016, 144).

\section{Reframing BATNAS in Sports Negotiation: Strategies for Optimal Win-Win Solutions}

Collaboration strategies and issue linkages may lead to optimal win-win solutions. As discussed in Win-Win or Hardball? (p.8).the first strategy is to manage one's agent. The most effective ways of doing so are by imposing a compensation scheme that rewards his added value during the process as well as by exercising principal's right to speak directly with the counterpart. The second strategy is in insisting to move to an interest-based negotiation style and create issue linkages. The third strategy is to do your homework and pertains to the pre-negotiation phase, i.e. examining the market. In other words, this means examining not only yours, but the constraints of the other side, as well as the outside factors. The fourth strategy is to apply creativity in the creation of better alternatives or options.

The compensation bonus or financial incentive for agents may trigger positive results if they make an extra effort during negotiations (Shropshire 2009, 143). This may be a way of achieving compatibility or interest alignment with the agent because agent's motivation is stimulated.

In order to create a mutual influence model, the principal as a manager of the process of principal-agent relationship, can offer performance-based contracts. This model distributes risk-sharing between the principal and the agent and transforms the agent into a primary negotiation party, a party of ownership (Crump \& Glendon, 2003, 17). The process of coaligning principal-agent interests may draw from coalition theory.

Another strategy is to create a negotiation game plan. This means several things. First it means coming up with a "range of possible outcomes or positive bargaining zone" (Shropshire 2009, 33) during the pre-negotiation phase. It also includes a formulation of one's leverage in the negotiation, the primary strategy and three other alternative strategies.

Strategies are backed up by creating leverage. This could be done in several ways. First, this could be achieved by lying in negotiations. This is similar to bluffing about the interest of potential bidders. Second, this could be achieved 
by timing (Shropshire 2009, 90) as both circumstances and values may change. Third, this could be achieved by maintaining consistency (Shropshire 2009, 93) of standards applied.

Determining one's characteristic bargaining style is expressed as "playing within yourself" (Shropshire 2009, 35) in the range of the well known five categories: avoider, competitor, collaborator, accommodator, and compromiser (Shropshire 2009, 40). The compromiser's motto is: "Let's split the difference" or "meet in the middle" and is usually favored by amateurs.

\section{Discussion}

\section{Reframing and Optimal Win-Win Solutions}

The process of reframing positional to interest-based negotiation requires reframing of needs (both survival and recognition needs). The preference order of BATNAs could change during the process of negotiation. The real question is to find creative ways for the smoothest transition among BATNAs.

During the interest-based negotiation the reframing of positions to interests could create different possible solutions and a win-win solution. Reframing the deeper interests lying in positions could bring a possible adaptation among parties and finding a common interest. Usually sports revolve around recognition needs on the top of the Maslow's pyramid. However, survival needs at the bottom of the pyramid are also involved. By mixing the first and the third levels of the pyramid the actor is mixing tangible things like resources with intangible things as the need for recognition.

BATNA is one's strategy if the other counterpart has more leverage (Fisher \& Ury 1991, 97 - 106). BATNA is a protective measure, an alternative, standard of measurement of any proposed agreement. Additional test is the formulation of a trip wire, a bottom line or an early warning mechanism whose purpose is to identify one "far from perfect agreement that is better than your BATNA" (Fisher and Ury 1991, 101).

There are several sources of leverage: the negotiation position, the team's/ athlete's position in the market (Falk 1992, 8), trade-offs and the negotiation style. Trade-offs represent the essence of the bargaining process and come under several forms (Falk 1992, 12). The first trade off is the length of the contract, the second is guarantees for either skill or injury. Guarantees provide security to players. The third trade off is current cash money versus deferred money/incentive bonuses, Cash money should be preferred. Negotiation styles depend on personality and situation and come under different approaches (Falk 1992, 15 - 18): 1) "high-ball, low-ball" (or meet in the middle approach), 2) hard-ball (when you have all the leverage), 3) bluffing, puffing and other forms of lying (which is unethical and causes distrust). The bottom line is credibility and flexibility. The negotiation style would determine whether the strategy is competitive or cooperative, the latter being preferred for optimal solutions (5 Tips to Winning...). 
The negotiator's aim is to facilitate the creation of a win-win solution. Communication is always context specific but creativity is the most difficult part of the process of achieving successful agreements. Creativity is mostly exhibited in the brainstorming session of the process.

Generally, business-to-business settings favor integrative negotiation style although it depends on the stage of the negotiation process which style will be preferred (Bala 2019).

Interest-based negotiation leads to a mutual gain. Flexibility and creativity are the two most vital skills during the process of inventing options for mutual gain (Fisher \& Ury 1991, 56 - 80). Creativity is built through a brainstorming session that stimulates consensus building (Fisher \& Ury 1991, 60).

\section{Mutual Gains Approach}

In order to reframe positions to interests or find the mutual interest for each of these tactics we have to start the analysis by the underlying question of the reason behind the need of a party in a given situation. If needs are compatible there could be a mutual interest. Once we answer this question (as the most important in the preparation phase of the negotiation) we could basically list all the BATNAs of the parties and then start negotiation to better those BATNAs or expand the frontier of possibilities for a bigger win-win outcome. By studying BATNAs we could analyze negotiating powers. Usually with sports we talk about asymmetric negotiation and power imbalance. To create a balanced negotiation we have to find ourselves in a win-win outcome (frontier of possibilities) in different contexts. A balanced negotiation requires all parties to meet at options that satisfy all of them, the standard being keeping a level where no one is disadvantaged.

Mutual gain bargaining is an alternative to the traditional, positional approach. Its premise is that a negotiated settlement is better than the other available alternatives (Geiger and McMurry 1999, 1) as both sides have something to gain from the negotiation. The more complex the problem, the more difficult it is to solve with positional bargaining. Positional bargaining can still be implemented when the interests of the parties are not interdependent and when future relationships between them have low priority (Geiger \& McMurry 1999, 4). Mutual gain or interest bargaining, although time consuming and requiring a level of trust, offers alternative solutions to complex problems through creativity.

Mutual gain bargaining works through the concept of NBS (next best solution), which is better than a no-deal negotiated settlement. The underlying assumption is that both parties should have more than one issue of interest. If both sides decide that their NBS is worse than a possible negotiated solution, then this is a prerequisite for using mutual gain bargaining (Geiger \& McMurry 1999, 7). The whole process of such bargaining includes six stages or steps: 1) identifying the mutual interests and establishing trust, 2) framing the issues of concern, 3) identifying the problems, 4) generating options through brainstorming, 5) evaluating options through joint 
analysis and 6) finalizing the settlement through formal documentation, which also includes establishing monitoring and dispute resolution mechanisms (Geiger and McMurry 1999, 13 - 17). The outcome of the most important, evaluation phase are the so called possible packages that may lead to mutual gain (What is Mutual Gain?...). Estimation of the BATNAs or main interests of both sides is made during the first stage. The brainstorming session provides the chance of inventing additional interests without committing (BCI's Mutual Gains Approach to Negotiation...).

\section{Conclusion}

Representative negotiations in sports may be considered as an example for other negotiations with agents as real estate negotiations or negotiations involving lawyers. BATNAs could be reframed mainly by the use of the following negotiation games: favors and ledgers leading to compromise and trade-off games. The bottom line is flexibility and leverage, i.e. issue linkages and it is possible in the mutual gain bargaining.

\section{NOTES}

1. The 11 negotiation games are explained in the second part of the "Essentials of negotiation" webinar entitled: "Strategy, Tactics \& Planning" .

\section{REFERENCES}

Bala, A., 2019. To What Extent Do Monetary Incentives Influence the Negotiation Behavior in Businessto-Business (B2B) Settings?, University of Twente, the Netherlands. [Retrieved on 2 May 2021]. Available from: http:// essay.utwente.n1/78443/1/Bala_BA_BMS.pdf

CBI's Mutual Gains Approach to Negotiation, Consensus Building Institute. [Retrieved on 1 May 2021]. Available from: https://www.cbi.org/article/ mutual-gains-approach/

Crump, L. \& Glendon, A. I., 2003. Towards a Paradigm of Multiparty Negotiation, International Negoatiation, 8(2): 197 - 234. [Retrieved on 30 April 2021]. Available from: https://citeseerx.ist.psu.edu/viewdoc/download ?doi $=10.1 .1 .336 .6374 \&$ rep $=$ rep $1 \&$ type $=$ pdf

Davis, T., 2001. What Is Sports Law?, Marquette Sports Law Review, 11 (2), Article 7, $211-244$ [Retrieved on 30 April 2021]. Available from: https:// scholarship.law.marquette.edu/cgi/viewcontent.cgi?article $=1517 \&$ context $=$ sportslaw

Dimov, P., 2016. Voinata - vechnata bolest na obstestvoto. Evolycia na koncepciite za vodene na voina. ,Balgarska nauka“ (90), 138 - 148 ISSN: 1314-1031, [Retrieved on 5 April 2021]. Available from: https://image. nauka.bg/magazine/bg-science90.pdf [in Bulgarian] 
"Essentials of negotiation" webinar entitled: "Strategy, Tactics \& Planning", Canadian International Institute of Applied Negotiation. [Retrieved on 8 March 2017]. Available from: https://ciian.org/

Falk, D. B., 1992. The Art of Contract Negotiation, 3 Marq. Sports L. J. 1. [viewed 30 April 2021]. Available from: https:/core.ac.uk/download/ pdf/148695624.pdf

Fisher, R. \& Ury, W. L., 1991. Getting to Yes: Negotiating Agreement Without Giving In. London: Penguin Books.

Geiger, M. E. \& McMurry, B., 1999. MUTUAL GAINS BARGAINING, LLP. [Retrieved on 1 May 2021]. Available from: https://www.blaney.com/files/ article mutual gains.pdf

Heitner, $\bar{D}$., 2015. 5 Tips to Winning a Big Sports Negotiation, [Retrieved on 30 April 2021]. Available from: https:/www.inc.com/darren-heitner/5-tipsto-winning-a-big-sports-negotiation.html

Murphy, B. J., n.d. Sports Contract Negotiation, Attorney \& Counselor at Law. [Retrieved on 30 April 2021]. Available from: https://entertainmentiplaw. com/sports-contracts-and-marketing/sports-contract-negotiation/

Rubin, J. Z. \& Sander, F. E. A., 1988. When Shall We Use Agents? Direct vs. Representative Negotiation, Negotiation Journal October 1988, p.395 - 401.

Shropshire, K. L., 2009. Negotiate Like the Pros: A Master Sports Negotiator's Lessons for Making Deals, Building Relationships, and Getting What You Want. New York: McGraw Hill.

Steinberg, L., 2016. How to Be A Great Sports Agent-Contract Negotiations, SportsMoney. [Retrieved on 1 May 2021]. Available from: https://www. forbes.com/sites/leighsteinberg/2016/07/11/how-to-be-a-great-sports-agentcontract-negotiations/?sh=76889690698f

What is Mutual Gain?. [Retrieved on 2 May 2021]. Available from: https:// www.pon.harvard.edu/tag/mutual-gain/

Win-Win or Hardball?, Learn Top Strategies From Sports Contract Negotiations, Special Report. (2012). Program on Negotiation, Harvard Law School. [Retrieved on 30 April 2021]. Available from: https://www.pon.harvard.edu/ freemium/win-win-or-hardball-learn-top-strategies-from-sports-contractnegotiations/

$\triangle$ Hristina Dobreva

https://orcid.org/0000-0002-2581-4356

Rakovski National Defence College

Sofia, Bulgaria

E-mail: h.dobreva@rndc.bg 